\title{
Evasão maternal: que políticas as empresas vêm adotando para não perder suas funcionárias para a maternidade? Um estudo multicaso
}

\author{
Maternal evasion: what policies do companies have been adopting in order to not lose their \\ employees for maternity? A multicle study \\ Evasión materna: ¿qué políticas están adoptando las empresas para no perder a sus empleados por \\ maternidad? Un estudio multiculo
}

Recebido: 07/01/2021 | Revisado: 08/01/2021 | Aceito: 09/01/2021 | Publicado: 10/01/2021

Lídia Maia Moreira

ORCID: https://orcid.org/0000-0001-9525-0341 Universidade Federal de Lavras, Brasil E-mail: lidiamm172@gmail.com

Marcelo Oliveira Junior

ORCID: https://orcid.org/0000-0001-9683-4306 Universidade Federal de Lavras, Brasil

E-mail: marcelo.junior2@estudante.ufla.br

Rafael Rodolfo Sartorelli Sadocco

ORCID: https://orcid.org/0000-0002-2051-379X Universidade Federal de Lavras, Brasil E-mail: rafael.sadocco@gmail.com

Dione Welder de Faria

ORCID: https://orcid.org/0000-0001-9259-822X Universidade Federal de Lavras, Brasil E-mail: dionewelder279@gmail.com Leandro Carvalho Bassotto

ORCID: https://orcid.org/0000-0002-0508-9177 Universidade Federal de Lavras, Brasil

E-mail: bassotto.lc@gmail.com

Ana Luiza Cordeiro Pereira

ORCID: https://orcid.org/0000-0002-7178-6552 Universidade Federal de Lavras, Brasil E-mail: analuizacordeiro96@gmail.com

Patrícia Aparecida Ferreira

ORCID: https://orcid.org/0000-0002-0847-5890 Universidade Federal de Lavras, Brasil E-mail: paf@ufla.br

Alberdan José da Silva Teodoro

ORCID: https://orcid.org/0000-0002-9315-218X Universidade Federal de Lavras, Brasil

E-mail: alberdan.teodoro@estudante.ufla.br

Iasmin Ribeiro Diniz

ORCID: https://orcid.org/0000-0002-5762-7491 Unilavras Centro Universitário, Brasil E-mail: iasminrd@hotmail.com

Fernando Ferrari Putti

ORCID: https://orcid.org/0000-0002-0555-9271 Universidade Estadual Paulista, Brasil E-mail: fernando.putti@unesp.br

\begin{abstract}
Resumo
Este trabalho buscou identificar quais as políticas empresariais que estão sendo adotadas pelas empresas para reter as colaboradoras mães, uma vez que se entende que a saída dessas profissionais acarretaria em prejuízo para as organizações, o que é pouco estudado pela academia. Para tanto, utilizou-se a metodologia de estudo de caso-múltiplo, por meio de duas entrevistas e duas análises documentais, todas elas em empresas de grande porte. Os dados obtidos foram submetidos à análise por meio da categorização de maneira emergente, ou seja, as categorias de análise foram surgindo a partir dos resultados. Por meio disso, foram criadas três categorias de análise e, majoritariamente, a categoria "tipos de benefícios" foram os que mais se destacaram. Os resultados indicaram que as empresas acabam concentrando seus esforços em benefícios pontuais, muito próximos aos da legislação vigorante em cada país, e não necessariamente um arcabouço de políticas empresariais que poderiam de fato atender e reter as colaboradoras mães. Palavras-chave: Maternidade; Políticas empresariais; Evasão.
\end{abstract}




\begin{abstract}
This paper searches to identify the policies that are being adopted by companies to retain employees that are mothers, since the leaving of those professionals would result in several issues for the companies, once there are only few studies about this subject in the academic scenario. To do so, it was used the multiple case study method, through two interviews and two documents analysis, all of them in large companies. The data obtained was submitted to analysis by means of the categorization in an emergent manner, or else, the categories of analysis are derived from the results. Through this, three categories of analysis were created, however, the one category that concentrated the biggest highlight of these categories was the "types of benefits". The results indicate that companies end up concentrating their benefits on specific points, very close to the legislation in force in each country, and do not use a business policies framework that could attend and retain their mother employees.
\end{abstract}

Keywords: Maternity; Business policies; Evasion.

\title{
Resumen
}

Este trabajo busca identificar qué políticas corporativas están adoptando las empresas para retener a las madres colaboradoras, ya que se entiende que la salida de estas profesionales resultaría en pérdidas para las organizaciones, lo cual es poco estudiado por la academia. Para ello se utilizó la metodología de estudio de casos múltiples, a través de dos entrevistas y dos análisis documentales, todos ellos en grandes empresas. Los datos obtenidos fueron sometidos al análisis mediante la categorización de forma emergente, es decir, las categorías de análisis surgieron de los resultados. A través de esto se crearon tres categorías de análisis, pero en su mayoría, la categoría "tipos de beneficios" fue la que más se destacó. Los resultados indicaron que las empresas terminan concentrando sus esfuerzos en beneficios específicos, muy cercanos a los de la legislación vigente en cada país, y no necesariamente en un marco de políticas corporativas que realmente puedan servir y retener a las madres colaboradoras.

Palabras clave: Maternidad; Políticas comerciales; Evasión.

\section{Introdução}

Como vem sendo alardeado por diversos órgãos de imprensa (Maes, 2017; Brasil, 2017; Olivieri, 2019), a conciliação entre maternidade e trabalho retrata uma problemática presente na gestão de empresas, exigindo que tais entidades saibam como acolher as profissionais, principalmente no momento em que as mães retornam da licença maternidade, posto que esse período tende a ser bastante desgastante psicologicamente (Trevisan, 2015; Dalpino, 2018). Fernandes et al. (2018), apontam que as dificuldades para as mães estão tanto no campo judicial como no empresarial. As autoras sugerem que ao redor do globo, existem centenas de milhões de trabalhadoras desguarnecidas de suporte para exercerem apropriadamente suas atividades maternais, em virtude da ausência de proteção legal para tal. Já na esfera micro, se essas mães não contam com suporte hierárquico multicanal - suporte em todas as diversas camadas que compõem uma empresa - acabam por enfrentar muitos desafios inglórios.

Isso se dá em virtude de uma crença cultural de que as condutas maternais, como a amamentação, são uma decisão exclusiva da mulher, e não uma necessidade coletiva. Por esse motivo, as autoras defendem legislações, políticas e atitudes sociais para reverter o cenário. Dentro dos domicílios também é possível presenciar uma situação desfavorável às genitoras, onde muitas vezes se presencia que os esforços por partes dos homens são meramente secundários, recaindo sobre as mulheres mais tarefas e funções, motivo pelo qual elas tendem a sofrer maior sobrecarga com as funções parentais. Isso poderia ser explicado pelo fato de os pais conseguirem manter seus espaços pessoais e de lazer, diferentemente das mães, cuja realidade se mistura com ado lar (Pasinato \& Mosmann, 2016).

As mulheres além de serem acometidas por essa sequência de situações desfavoráveis no âmbito pessoal, ainda tendem a receber salários inferiores aos das mulheres sem filhos e homens, em geral. Tal fato poderia ser explicado pelo tempo que ficam afastadas do mercado profissional durante a maternidade, a perda de expertise e know-how, além do aumento da dificuldade para estudarem e se manterem atualizadas. Ademais, os empregadores geralmente compartilham da crença que as tarefas domésticas ficam concentradas na ala feminina do lar, o que acarretaria em menor produtividade dentro da empresa (Botello e Alba, 2014). Como visto, o conjunto de fatores é bastante desfavorável às mães nas organizações, e isso pode ser corroborado por pesquisas conduzidas por consultorias de recursos humanos $(\mathrm{RH})$ e divulgadas em grandes mídias. 
A consultoria Robert Half fez uma pesquisa com 1.775 diretores de RH em 2013, que apontou que em 63\% das empresas entrevistadas, mais de 50\% das trabalhadoras não retornam às companhias após o nascimento dos filhos (Mamona, 2013). Outra pesquisa revelada pela empresa Catho, também de consultoria, indica que 30\% das mulheres abandonam o mercado para cuidar das crianças (Carmo, 2019; Trevizan, 2019).

Embora os números supracitados não contenham o rigor acadêmico, sugerem a importância do tema e indicam que as empresas podem estar perdendo excelentes colaboradoras por não conseguirem se adequar e ofertar condições laborais propícias, por conseguinte, essa debandada resultaria tanto em perda operacional como financeira. Isso justificaria trabalhos acadêmicos como este, que busca responder à pergunta: que tipo de políticas empresariais as companhias estão adotando para reter suas colaboradoras mães? Nota-se que o objetivo deste trabalho não está concentrado em responder perguntas sobre pautas sociológicas ou legais, e sim empresariais. Para responder esta pergunta, propôs-se aqui uma pesquisa exploratória qualitativa, utilizando um estudo multicaso, tomando por base duas entrevistas semiestruturadas e duas análises de documentos institucionais, que foram assim examinadas.

\section{Referencial Teórico}

Para se atingir o bojo da problemática, o que exige um apanhado histórico, capaz de contextualizar o atual cenário, esta seção está dividida em quatro temas que permeiam a discussão acerca da maternidade e as políticas empresariais para acolhimento das profissionais. São eles: (i) a inserção da mulher no mercado de trabalho, com a historicidade do processo até os dias atuais; (ii) principais marcos legais no Brasil; (iii) maternidade e trabalho; e, por último, (iv) as políticas empresariais para a maternidade.

\subsection{A inserção da mulher no mercado de trabalho: panorama histórico e atual}

De acordo com Uchôa (2016, p. 19), "a discriminação e os preconceitos estão presentes nas sociedades há anos, incluindo diversos temas que envolvem as mulheres, e tais fatos se manifestam inclusive no campo laboral". Para esse autor, ao longo da história da humanidade, os papéis designados para cada gênero obedeceram em certa medida questões de necessidade de subsistência das mais diversas, ao passo que também foram movidos por paradigmas modelados por características sociais inerentes a cada realidade.

Lauschner, Cavalcante e Torres (2012) apresentam que quando a humanidade adotava o sistema de caça e coleta, a taxa de natalidade era baixa, dado que a migração forçada requeria um baixo número de filhos, o que permitia que as mulheres contribuíssem com bens econômicos importantes. Essa situação mudou em razão da agricultura e domesticação dos animais, uma vez que esses afazeres desprendiam menor tempo de labor e diminuíam drasticamente a necessidade de mobilidade, permitindo assim um aumento na taxa de natalidade, e, por conseguinte, um maior isolamento feminino da atividade produtiva/econômica e o encaminhamento das mulheres para a atividade materna/doméstica.

Segundo Hobsbawn (2004), citado por Baylão e Schettino (2014), as mulheres começam a ocupar de fato o espaço social no mundo ocidental somente a partir da Revolução Francesa em 1789, onde passam a requerer melhor seus direitos e anseios, a buscarem instrução, além de começarem a ter alguma participação política. Explanam que a Revolução Industrial, no século XVIII, também foi fundamental para a inclusão das mulheres no mercado de trabalho, uma vez que elas começaram a ocupar cada vez mais cargos dentro da indústria têxtil, principalmente, porque esta oferecia trabalho sub-remunerado, o que permite depreender que até a Revolução Industrial as posições ocupadas pelas mulheres eram de baixa qualificação e baixa remuneração (Baylão \& Schettino, 2014).

Já Spricigo (2017) sinaliza que até a Revolução Industrial, as mulheres atuavam apenas na esfera doméstica, cabendo, exclusivamente, aos homens o papel de conduzir o progresso e transformar a realidade partilhada por todos. Isso se inverte por 
demanda do sistema de produção capitalista, que ao almejar diminuir o custo de produção, abriu espaço para esse tipo de mãode-obra mais barata. Outro ponto importante na compreensão da historicidade das mulheres no mercado de trabalho, no mundo ocidental, está relacionado ao fato delas terem ocupado postos de trabalho tanto durante como, também, após a Segunda Guerra Mundial. Isso se deu porque como muitos homens voltavam mutilados ou com graves transtornos mentais, foi possível que as mulheres ocupassem cargos tanto nas empresas familiares como fora de casa (Baylão \& Schettino, 2014).

Já nas décadas que se seguiram ao fim da Segunda Guerra Mundial ocorreu uma profusão de mensagens publicitárias que condenavam a atividade profissional fora do espectro domiciliar, desaprovando mulheres que assim o fizessem. Fora isso, mesmo nesses períodos turbulentos, manteve-se a elas remunerações inferiores aos homens, uma vez que essas mulheres eram percebidas como meras suplentes, sem a qualificação e a força física adequada para suplantá-los em igual medida (Lauschner, Cavalcante \& Torres, 2012).

Mais centrado no cenário brasileiro, Vasconcelos (2013) expõe que a participação das mulheres no mercado de trabalho pode ser analisada majoritariamente a partir de meados do século XIX até as décadas iniciais do século XX, quando a política brasileira era de atrair imigrantes de países europeus para compensar o fim da escravidão, colocando tanto mulheres como crianças estrangeiras para labutar nas lavouras e nas fábricas.

Por sua vez, as mulheres negras foram condicionadas a serviços menos valorados, tais como: empregadas domésticas, cozinheiras, lavadeiras, doceiras, vendedoras de rua e até mesmo prostitutas. As mulheres que ocupavam postos nas fábricas nesse período apresentavam características similares: eram pouco escolarizadas, pobres, solteiras e sem filhos, além de não demonstrarem anseios reivindicatórios, uma vez que percebiam sua condição laboral como complementar aos ganhos familiares e transitória. Assim, segundo a autora, funcionaria como uma "reserva de mão-de-obra".

Ferreira (2004) apud Vasconcelos (2013) também destaca que com as mudanças nos modelos de trabalho a partir da década de 1970, aliadas a crises econômicas nacionais, ao avanço do toyotismo, e a fragmentação e flexibilização do trabalho, passou-se a requisitar profissionais multifacetados, criativos, polivalentes, multi especializados, entre outros pontos que são ligados, segundo a autora, à natureza feminina. Todavia, essas profissionais distanciaram-se daquelas supracitadas, e seriam, portanto: melhor formadas, mães, casadas e mais velhas. Este movimento se intensifica a partir da década de 1990.

Essas condições podem ser vistas meramente como negativas dado que, a divisão sexual do trabalho é, portanto, um instrumento que reforça tanto a dominação, quanto a exploração das mulheres. Dominação, pois, quando as mulheres se detêm apenas ao trabalho doméstico para sua família perdem autonomia econômica, tornam-se dependentes e subordinadas a quem garante sobrevivência familiar, em geral, os homens, marido, filhos, etc. Já a exploração é resultado da dupla ou tripla jornada de trabalho, uma vez que, quando as mulheres decidem conquistar autonomia financeira, trabalhando no espaço público, são submetidas a uma jornada de trabalho junto à família e outra para ganhar dinheiro (Vasconcelos, 2013).

Ao se analisar os desdobramentos das reflexões históricas levantadas até então, urge-se debruçar sobre dados estatísticos para perceber quantitativamente como esse cenário veio se transformando do meio do século XX até chegar na atual formação das primeiras décadas do século XXI. Andrade (2016), por exemplo, avalia dados do Instituto Brasileiro de Geografia e Estatística (IBGE) para investigar o expressivo crescimento das mulheres no mercado de trabalho brasileiro ao longo da segunda metade do último século. Segundo a autora, apenas 13,6\% das mulheres integravam a População Economicamente Ativa em 1950 (tomando por base somente trabalhadores formais e não aquelas que praticavam labores domésticos). Entretanto, o censo de 2010 mostrou que 49,9\% constavam como ativas economicamente.

Esses dados são reforçados pela Pesquisa Nacional por Amostra de Domicílios (PNAD) feita entre 2004-2014 pelo IBGE que apresenta taxas de ocupação masculina perto de $76 \%$, enquanto as taxas femininas estariam na casa dos $52 \%$. Contudo, a PNAD contempla a taxa de ocupação os trabalhos formais e informais que geram renda (IBGE, 2017). Andrade (2016) também cita relatórios de Pesquisa de Emprego e Desemprego (PED) 2011-2012, elaboradas pelo Departamento 
Intersindical de Estatística e Estudos Socioeconômicos (DIEESE) e fontes do Instituto de Pesquisa Econômica Aplicada (IPEA) de 2016, para relatar que parece ocorrer um esgotamento da ascensão feminina no mercado de trabalho.

Em outras palavras: aparentemente, há motivos para se crer que dificilmente as mulheres tomarão uma taxa de ocupação acima de $60 \%$, posto que desde 2005 a oscilação vem sendo sempre negativa. Todavia, vale pontuar a título de comparação, que em todo mundo a única região em que a taxa de ocupação feminina supera os 60\%, é no Leste Asiático com $64 \%$. Contudo, o IBGE $(2017 ; 2012)$ apontou que há uma brutal separação da presença feminina de acordo com o ramo da atividade.

A participação mais efusiva de mulheres se comparada ao de homens se dá nos ramos de administração pública (64,1\%) e serviços domésticos $(94,8)$. Nos demais, as mulheres sempre estão quantitativamente atrás dos homens, aparecendo com as seguintes taxas: 42,5\% no comércio; $42 \%$ nos serviços prestados a empresas; $36 \%$ na indústria; $6,1 \%$ na construção; e $41,6 \%$ nos outros serviços. De qualquer forma, é importante destacar que a taxa de participação de mulheres com mais de 11 anos de estudo é maior do que a de homens em diversos segmentos, como no comércio (respectivamente $51,5 \%$ e $38,4 \%$ ) e construção (respectivamente $55,4 \%$ e $15,8 \%$ ).

Uchôa (2016) ainda apresenta que os homens aparecem com uma menor taxa de desocupação (52,3\%) que as mulheres $(69,7 \%)$, considerando por desocupado aqueles que procuraram emprego nos últimos 12 meses e não conseguiram. No campo legal, a questão da maternidade é um dos aspectos fundamentais para compreender como a relação mulher e trabalho é vista aos olhos do governo. Pequeno progresso vem ocorrendo desde a metade do século XX, conforme apontam alguns autores e que serão discutidos no próximo tópico.

\subsection{Principais marcos legais no Brasil}

Ansiliero e Rodrigues (2007) citam que a licença gestante começou com a Consolidação das Leis do Trabalho (CLT), oficializada pelo Decreto-Lei $n^{\circ} .5 .452$, de $1^{\circ}$ de maio de 1943, que estabeleceu que a licença gestante duraria quatro semanas antes do parto, oito depois, sendo que o salário deveria se manter integral nesse período. Segundo Lessa (2007), embora esse prazo de remuneração fosse significantemente curto, isso já era suficiente para dificultar o ingresso de mulheres no mercado de trabalho, já que a integralidade do salário era paga pelo empregador.

Só a partir de 1974, o benefício passou a ser suplantado pela Previdência Social. Pode-se pontuar que foi com a Constituição Federal de 1988 que o conceito do que deve vir a ser a licença gestante foi sancionado próximo do que se conhece atualmente, e passou a ser um direito social com duração de cento e vinte dias, valendo tanto para as mulheres empregadas e seguradas pela Previdência Social (urbana e rural), como também para as trabalhadoras avulsas e domésticas (Ansiliero e Rodrigues, 2007). Com a reforma da Legislação Trabalhista que foi aprovada na Câmara dos Deputados em abril de 2017, alguns autores, como Guimarães e Martinez (2017), consideram que no que tange às gestantes, essas modificações foram um grande atraso.

Apontam eles que determinadas alterações prejudicarão sobremaneira as gestantes, colocando tanto a futura mãe como a criança em risco de vida. Autorizou-se, por exemplo, a gestante a trabalhar em locais insalubres (algo que havia sido erradicado anteriormente), ainda que isso só possa ocorrer quando a grávida se apresente de maneira voluntária juntamente com documento médico, ao que os olhos desses autores mostram que a discussão sobre as leis que protegem os trabalhadores continua vívida, uma vez que a empresa goza de um aparato instrumental capaz de subjugar e prejudicar as colaboradoras.

Por fim, desde 2017 tramita o Projeto de Lei do Senado nº72, de 2017, para majorar o prazo da licença-maternidade, ampliando-o de 120 para 180 dias, além de consentir ao pai acompanhar a mãe em consultas e exames durante a gravidez. Esse projeto foi aprovado pela Comissão de Assuntos Sociais, o que resultará em uma possível alteração desse prazo, caso seja 
aprovado pela Câmara dos Deputados e sancionado pelo presidente. Todavia, tal projeto encontra-se parado há cerca de dois anos (Brasil, 2018).

\subsection{Maternidade e Trabalho}

A superestrutura por tradição fundamenta a função social feminina a partir da maternidade, aportada na estrutura familiar, e pelos meios em que a figura feminina se sujeita à posição de cuidadora. No entanto, a partir das transformações sociais e tecnológicas no que tange às funções sociais de gênero, surgem contingências estruturais e infra estruturais que substanciam a produção de novos padrões comportamentais femininos, com contingências de reforço da autonomia sexual feminina e consequente controle da gestação (Fonseca, 2011).

Fundamentado na ideia de que a mulher passou por grande ascensão no mercado de trabalho e na sociedade contemporânea, Grant (2001) pontua que em virtude disso a mulher passa a definir por si as diretrizes de sua vida, tanto no que tange a optar por casar, se relacionar, ter filhos, bem como não seguir nenhum desses caminhos, o que implica nas várias possibilidades de construção de sua trajetória tanto pessoal quanto profissional. Sendo assim, é necessário que se estude um dos possíveis cenários da construção profissional da mulher, onde se concilia o trabalho com a maternidade.

Para tanto, embasando-se em uma pesquisa realizada por Fiorin, Oliveira e Dias (2014), pôde-se perceber que as mulheres concebem o trabalho externo ao lar como uma fonte de satisfação e reconhecimento social. Embora as mulheres considerem que a maternidade pode lhes oferecer realização pessoal, tal fato pode representar um empecilho para o seu crescimento profissional devido, muita das vezes, a necessidade de renúncia de planos vinculados ao trabalho. Sendo assim, percebe-se que a ideia da maternidade como única forma de as mulheres se sentirem realizadas emocionalmente está sendo desconstruída, visto que a carreira profissional desempenha papel central na vida de muitas mulheres, fazendo-as, inclusive, adiar o nascimento de um filho para se dedicar, primeiramente, à construção da carreira profissional.

Por outro lado, Basilio (2014) cita que em uma pesquisa realizada pela Microsoft com dois mil funcionárias e 500 empregadores nos Estados Unidos, foi possível descobrir que muitas mulheres melhoram o desempenho profissional após a chegada dos filhos. Entre as principais mudanças, está a capacidade de realizar várias tarefas ao mesmo tempo, a gestão mais organizada do tempo e o aumento das relações cordiais com outros colegas de trabalho. Além disso, maior parte dos empregadores entrevistados afirmaram que mulheres com filhos trabalham melhor em equipe do que as que ainda não são mães.

Ademais, a pesquisa mostrou que, o sucesso profissional das mães pode ser pelo fato da rotina mais flexível. De acordo com os pesquisadores, o home office, ou seja, o "trabalho em casa" e os horários alternativos dão a elas mais tempo para gastar com seus filhos e, então, elas conseguem se voltar ao trabalho de maneira mais relaxada e dedicada. Sendo assim, o fato de a mulher entrar na maternidade não representaria um empecilho em si para o seu crescimento profissional, visto que elas podem retornar de maneira muito mais ativa e produtiva para a organização. Posto isso, é possível apreender que o fato de a mulher querer ter filhos para garantir sua realização pessoal, não necessariamente, a prejudicará na construção de sua carreira, tendo em vista os grandes benefícios que a maternidade pode trazer para a vida profissional da mulher. No entanto, é válido que se compreenda o papel das empresas no acolhimento às mães, de modo a ser propícia a conciliação da maternidade com o trabalho, o que será discutido no tópico abaixo.

\subsection{Políticas empresariais para a maternidade}

Carvalho Neto, Tanure e Andrade (2010) destacam que a cultura corporativa ainda é masculina e que, em virtude disso, as mulheres são obrigadas a se adaptarem a ela. Mesmo assim, passam por situações bastante singulares quando ocupam altos cargos em empresas, ao serem vítimas de preconceitos, tais como só terem ascendido profissionalmente por usarem sua 
sexualidade ou por se comportarem como homens, e isso se dá exatamente por conta dessa percepção de que a cultura corporativa ainda é masculina.

Umeda e Trindade (2004) destacam que o conceito de políticas empresariais é algo muito ardiloso para se definir, em virtude da profusão de contextos em que seriam aplicadas, uso generalizado da palavra, da problemática envolvendo a tradução, das discordâncias entre autores, etc. Todavia, esses autores, após levantamento bibliográfico/conceitual - que objetivava levantar exatamente essa definição - conseguiram determinar algumas características sobre as políticas empresariais. Eles apontaram que as políticas empresariais tendem a sugerir um conjunto de guias, orientações e parâmetros, intermediando o planejamento e a execução, diminuindo dúvidas e incertezas nos processos decisórios, ainda que não sejam responsáveis por definir as decisões, mas encaminhá-las.

Mais, almejam o longo prazo enquanto flexíveis para se adaptar às novas condições de mercado. Até a década de 1980, as empresas pareciam ser bastante assépticas em relação a sua composição, descartando minorias e renegando as diferentes subjetividades de seus empregados. Porém, a partir dessa data, as organizações começaram a dar valor à heterogeneidade em seus quadros de empregados, criando políticas motivadas pelas ideias de que isso deixaria o ambiente mais democrático e diversificado. No entanto, a criação e aceitação de políticas desse tipo participam de uma rede de discursos das empresas, sendo que um dos motivos para o acolhimento às minorias partilha de práticas complexas, como projetar e legitimar uma nova percepção da organização no cidadão empregado e na comunidade, bem como no mercado (Saraiva \& Irigaray, 2009).

Pinheiro e Gois (2013) destacam que é possível perceber um padrão biótico dos profissionais das empresas, sendo eles brancos, homens e heterossexuais em sua predominância, e o pretenso desalinhamento com esse perfil pode sugerir que a pessoa esteja em desacordo, o que poderia levar a discriminação. Esses autores fazem um recorte binário entre os tipos antagônicos dentro das empresas que poderiam gerar conflitos, sendo um deles, o gênero.

Embora o labor feminino venha ganhando espaço há cerca de um século e tenha conseguido avançar em diversos aspectos, como por exemplo, crescimento da escolaridade e empregabilidade das mulheres, ainda está muito aquém dos homens no que tange salários e posições hierárquicas, mesmo sem que esteja claro o motivo que gera essa discrepância. Uma hipótese levantada é de que as mulheres, muita das vezes, por conciliarem uma dupla jornada de maternidade e vida profissional, acabam por disporem de pouco tempo e disposição para galgar postos de maior relevância nas empresas. No entanto, ainda assim, empresas como Walmart adotaram políticas estratégicas para inclusão, o que permitiu que essa firma tivesse $45 \%$ de mulheres em seus quadros, sendo que 32\% ocupam cargos de chefia (Pinheiro \& Gois, 2013).

Posto isso, pode-se perceber o caráter recente desta linha de pesquisa visto que, até então, ainda não são encontradas grande número de políticas específicas relacionadas ao acolhimento da profissional e mãe. Sendo assim, é válido analisar as possíveis práticas existentes em algumas empresas de forma a compreender a relevância da adoção de tais políticas.

\section{Metodologia}

Optou-se aqui pelo uso do estudo de casos múltiplos, que é definido por Yin (1984, p.23) como: “[...]uma pesquisa empírica que investiga um fenômeno contemporâneo em seu contexto natural”. O estudo de casos múltiplos permite também verificar similaridades e discordâncias dentro de uma mesma seara (Yin, 2001). Conta com abordagem qualitativa com caráter descritivo, e é caracterizada como pesquisa exploratória, que assim como dito por Vergara (2009), é utilizada quando há poucos estudos voltados à temática pesquisada e pode servir, também, para aumentar o grau de familiaridade com fenômenos relativamente desconhecidos e obter informações sobre um contexto particular da vida real.

Para se escolher as empresas, optou-se pela seleção de amostra por tipicidade, em outras palavras, trata-se de uma das formas da amostragem por conveniência, constituída pela seleção de elementos que os realizadores da pesquisa consideram representativos da população-alvo, que atendem a expectativa ainda que não sejam essencialmente representativos da 
totalidade (Vergara, 2009). Elegeu-se empresas grandes, com mais de dez mil funcionários, que tivessem departamentos de RH bem estruturados. Demandou-se por duas grandes empresas brasileiras e duas estrangeiras que atuassem no Brasil, sendo que todas elas deveriam ser de segmentos diferentes.

Os nomes das mesmas foram preservados. Para atingir ao objetivo deste artigo, a técnica utilizada para a coleta de dados foi dupla: entrevista e análise documental. Por meio de um questionário semiestruturado, a primeira parte se deu por aplicá-lo em duas grandes empresas. Uma companhia respondeu a entrevista por e-mail, e a outra através de uma entrevista por telefone. As questões incluídas no questionário foram elaboradas com base no referencial teórico previamente desenvolvido.

A segunda técnica adotada foi a da pesquisa documental, através de documentos disponibilizados no website das companhias. Sendo assim, fez-se uso da pesquisa documental que, como citado por Vergara (2009), permite toda sorte de documentos conservados no interior de órgãos públicos ou privados de qualquer natureza, independente da finalidade para qual foram desenvolvidos. Trata-se de um método caracterizado pela análise de documentos ainda não tratados cientificamente. Para demarcação das categorias de análise, escolheu-se pela categorização de maneira emergente, ou seja, as categorias de análise foram surgindo a partir dos resultados (Moraes \& Galiazzi, 2006). Os dados foram coletados entre setembro e dezembro de 2018.

\subsection{Unidades de análise (empresas analisadas)}

Para analisar os tópicos até então discutidos, foram abordadas as seguintes empresas:

i. A primeira empresa é brasileira, surgida no interior de São Paulo, do segmento varejista, conta com aproximadamente 740 lojas no país, 20 mil funcionários, e tem 61 anos de existência. Será denominada como Empresa A. Essa empresa respondeu a entrevista por e-mail, alegando que optou por participar desta forma, em virtude de as respostas estarem polarizadas dentro da empresa, uma vez que diversas diretorias e diretores participariam da elaboração de seus processos, o que impediria uma entrevista.

ii. A segunda empresa é do segmento alimentício, é suíça, fundada em 1866, e entrou no mercado brasileiro em 1875. Atua em 194 países, com fábricas em 86, sendo 31 delas no Brasil. Ainda no Brasil, possui 16 mil colaboradores e distribui seus produtos em mais de 1.600 municípios. Será denominada como Empresa B. Os dados concernentes à essa empresa foram analisados de forma documental, por meio da sua "Política Internacional para a Maternidade”, divulgada em 2015. Maiores esclarecimentos não foram possíveis, dado que as tentativas de contato não foram respondidas.

iii. A terceira empresa é brasileira, criada em São Paulo, do segmento financeiro, sendo o maior banco privado do Brasil. Fundado em 1945, conta com 96 mil funcionários, cinco mil agências físicas em todos os Estados do Brasil, e mais de 74 milhões de contas correntes (entre pessoas físicas e jurídicas) cadastradas. Denominada empresa C, teve seus dados analisados por meio da disposição de suas políticas voltadas para a maternidade, que se encontram em um guia discriminado como "Compromisso para os Direitos Humanos", onde a empresa busca assegurar o estabelecimento desse com seus colaboradores e demais stakeholders, tomando como base os Princípios Orientadores, criado pela Organização das Nações Unidas sobre Empresas e Direitos Humanos, segundo o parâmetro "Proteger, Respeitar e Reparar" firmado em 2011.

iv. A quarta empresa é americana, fundada oficialmente em 1888, e atua no Brasil desde 1965, no setor de mineração. Conta com mais de 11 mil funcionários no mundo todo, sendo mais de mil funcionários no Brasil. A empresa D, concedeu uma entrevista por meio de uma Business Partner do departamento de Recursos Humanos da companhia, seguindo o modelo de questionário semiestruturado desenvolvido para esta pesquisa. 


\section{Resultados}

Para se realizar a análise dos resultados, fez-se as seguintes categorizações, baseadas nas confluências de tópicos encontrados. Serão discutidos nos itens subsequentes, os seguintes tópicos (i) tipos de benefício; (ii) abrangência; (iii) implementação.

\subsection{Tipos de benefícios}

\subsubsection{Empresa A}

A Empresa A tem cinco benefícios explícitos, tipificados e aparentes, sendo eles: horário flexível tanto para mães como pais poderem estar presentes em compromissos assumidos com seus filhos, como por exemplo, reunião escolar, acompanhamento médico, etc.; "Cheque Mãe" são programas da empresa, que ofertam um valor extra de $\mathrm{R} \$ 250$ mensais para auxiliar as mães que se responsabilizam por seus filhos (mesmo que tenham os pais presentes); "Cheque Educação Especial", criado em 2006, também tem o valor extra de $\mathrm{R} \$ 250$ mensais, e é dedicado aos colaboradores (mães ou pais) que têm filhos com algum tipo de deficiência; "Mamãe Bebê", foi criado em 2012 pelo Núcleo Social e Benefícios, e garante diversos auxílios (reembolso da coparticipação dos valores de consultas e exames referentes ao pré-natal; Livro do Bebê; acompanhamento telefônico durante o período gestacional por equipe especializada em caso de gravidez de risco; e, finalmente, a "Licença Maternidade", que desde 2017 garante que todas as mulheres grávidas tenham direito a 60 dias, além dos 30 dias de férias, de afastamento remunerado para dar toda a assistência que a criança necessita.

\subsubsection{Empresa B}

A Empresa B, promove diversos tipos de garantias a todas suas colaboradoras, independentemente de onde se encontram. Destacam-se assim, os seguintes benefícios: mínimo de 14 semanas remuneradas de licença-maternidade, sendo que a funcionária pode optar por se manter afastada por até seis meses, todavia, a remuneração a partir da décima quarta semana estará condicionada às práticas legais e/ou locais de cada região; essas práticas se estendem não apenas às mães, mas a qualquer um que seja o principal responsável pela criança (incluindo pais ou pais adotivos); após o término da licença maternidade, todas as colaboradoras têm o direito de retornar ao mesmo cargo - ou equivalente - ao que se encontrava; horários flexíveis e demais tipos de arranjos, como trabalho compartilhado, horário parcial, etc., desde que esteja acordado com as políticas de flexibilidade no ambiente de trabalho da empresa; ambiente de trabalho propício à amamentação, contando com diversas possibilidades de pausa para tal, e salas amoldadas para que as lactantes possam tirar leite ou amamentar em um ambiente relaxante (as salas são implantadas em todas os escritórios centrais e unidades com mais de 50 funcionárias).

\subsubsection{Empresa C}

A Empresa C, com a "Política de Apoio às Mães e Gestantes" estabelece vários procedimentos e benefícios a serem oferecidos às colaboradoras durante a gravidez, às mães que retornam da licença maternidade e aos pais, sendo eles: redução da carga horária durante o primeiro mês após término da Licença Maternidade; a avaliação de performance das colaboradoras que estiverem em Licença Maternidade, por pelo menos um mês, será realizada com base no último período trabalhado e a sua participação nos resultados do banco não sofrerá decréscimos; Licença Paternidade poderá ser prorrogada por até mais 15 dias além dos cinco já previstos. Além disso, busca ainda promover o auxílio à maternidade através da implementação dos seguintes programas: "Bebê a Bordo" programa focado nas orientações fundamentais a serem empregadas ao longo dos primeiros meses de gestação, como nutrição da gestante, primeiros cuidados com o recém-nascido, questões psicológicas, etc. "Canto da Mamãe", programa no qual a empresa concede local apropriado para retirada e armazenamento do leite materno durante o expediente. "Bebê em Casa", no qual a empresa viabiliza na primeira semana pós-parto a visita de uma enfermeira 
especializada na residência da família a fim de orientar acerca do aleitamento materno e primeiros cuidados com o recémnascido.

\subsubsection{Empresa D}

A Empresa D trabalha com a licença maternidade estendida por até 180 dias, como regra básica da empresa, e as mães também contam com flexibilidade para sair mais cedo, em situações nas quais poderiam levar os filhos ao médico, ou situações análogas. Isso posto, deve-se ressaltar que a empresa não conta com nenhum documento escrito que regule essas possibilidades de flexibilidade, o que faz da prática uma atividade informal, ou seja, não existe ainda uma regulação de política interna voltada para esses benefícios. Apesar disso, existe um programa interno, cujo o nome foi omitido nesta publicação, onde representantes do mundo inteiro discutem as melhores práticas para conciliar a maternidade, e como melhorar o espaço de trabalho para essas mulheres, permitindo inclusive que elas consigam atingir cargos de liderança dentro da empresa.

\subsection{Abrangência}

\subsubsection{Empresa A}

No que tange a abrangência das políticas aplicadas, a Empresa A fornece os benefícios igualitariamente à todas as colaboradoras, em todo território nacional, sem que ocorra nenhum tipo de distinção hierárquica.

\subsubsection{Empresa B}

$\mathrm{Na}$ empresa $\mathrm{B}$ é garantido à todas as colaboradoras da empresa os benefícios para acolhimento à maternidade, exceto em casos onde tais benefícios pudessem representar possível violação das leis locais.

\subsubsection{Empresa C}

Já na Empresa C está vigente a "Política de Acolhimento às Mães" e Licença Paternidade em todas as unidades da empresa no Brasil. No entanto, os programas "Bebê a bordo"; "Bebê em casa"; e "Canto da Mamãe" estão disponíveis apenas para as colaboradoras das unidades de São Paulo e da grande São Paulo no Brasil, onde se encontram os escritórios principais.

\subsubsection{Empresa D}

A empresa D estende seus benefícios à todas as colaboradoras e aos pais, todavia, nota-se na fala da representante da empresa, que os pais dificilmente utilizam desse serviço, acredita-se que isso se dá por fatores culturais.

\subsection{Implementação}

\subsubsection{Empresa A}

Esta companhia adotou essas práticas através de algumas propostas trazidas pelas colaboradoras (a empresa não soube informar como é feito o trâmite entre a idealização do projeto por uma funcionária até sua aplicação) como especificadas em detalhe e pela presidente do conselho. A partir disso, as demais ações foram introduzidas pela percepção da área de gestão de pessoas.

\subsubsection{Empresa B}

Não há informações disponíveis acerca de como se desenvolveu a implementação dessas políticas na companhia a partir do material analisado. 


\subsubsection{Empresa C}

Também não há nada especificado pela política empresarial de como se deu o movimento para implantação desses processos.

\subsubsection{Empresa D}

A empresa $\mathrm{D}$ conciliou os interesses da companhia com o das colaboradoras, embora não exista nenhum tipo de detalhamento mais claro sobre como isso foi estabelecido.

\section{Discussão}

Em um primeiro momento foi possível perceber que os tipos de benefícios ofertados foram muito mais passíveis de análise do que as demais categorias. Isso permite evidenciar que os demais pontos não são facilmente encontrados (nem nos documentos nem nas entrevistas), o que revela de antemão que a preocupação com o modelo de formação dessas políticas é secundária, o que pode acarretar tanto em prejuízo no modelo de implementação e execução dessas políticas, uma vez que sua concepção não é pré-estabelecida, como também na elaboração de políticas menos desejadas, já que as funcionárias, em maioria, não são inclusas no processo, nem tem instrumentos consolidados para fazê-lo.

Outros dados pertinentes que poderiam ter sido categorizados, como indicadores de resultado, funcionárias abrangidas e evasão de colaboradoras, foram, no máximo, superficialmente encontrados. Constata-se a partir disso que ou as empresas estão resguardando esses números, o que é pouco provável, ou elas não os têm. Não ter essas informações implica em um elemento que pode ser constatado nas duas empresas que foram entrevistadas: a informalidade. Faz-se assim perceptível que o trajeto histórico que culminou nas atuais culturas organizacionais, ainda reflete negativamente na forma pela qual as mulheres tendem a serem vistas nas empresas, permitindo que as mesmas flertem a ideia de deixar a companhia, uma vez que muito pouco é feito para conciliar suas demandas familiares com as profissionais.

Mais, vê-se que como mencionado no referencial a relevância da legislação, que como visto no exemplo da empresa B, segue sendo um agente importantíssimo no auxílio às trabalhadoras. Por fim, vê-se que há um total encaixe entre o que a literatura sugere, voltada exclusivamente para um conjunto de benefícios, e não uma política contínua de suporte com uma visão conciliatória da maternidade alinhada coma primeira, segunda e terceira infância. Não há uma visão de política para o ciclo infantil, o que se tem são ações pontuais para dar mais apoio à maternidade (o que já previsto é em legislação), tecnicamente, observando a maternidade como um ciclo muito curto e pontual, restrito muitas vezes à lactação, sem aporte para as demais atividades maternais ao longo da primeira, segunda e terceira infância.

\section{Considerações Finais}

A partir do que foi exposto, pôde-se notar que das duas empresas que consolidaram seus processos em políticas, percebe-se que apenas uma (a A) trabalha a ideia exposta no referencial teórico, que é necessário criar uma política interna multicanal, explícita, com diretrizes gerais para a atuação dos gestores e colaboradores. As demais empresas, principalmente a C, trabalham ações específicas e não necessariamente políticas empresariais para esta finalidade, ou seja, quando mencionam suas "políticas", percebe-se que na verdade elas nada mais são do que práticas, muitas vezes informais, do que de fato uma política empresarial, que acabam por compensar a ausência de um posicionamento explícito.

Assim, conclui-se que os esforços que estão sendo tomados para reter as trabalhadoras mães são deficitários, pontuais, e não podem ser configurados como "políticas empresariais". Outra conclusão que pode surgir deste ponto é que há uma aparente percepção que a preocupação empresarial com a maternidade deveria se dar majoritariamente na primeira infância, e 
que os anos posteriores (segunda, terceira infância, etc. até mesmo a adolescência) não demandariam maiores programas de acomodação permanente durante o crescimento das crianças.

Percebeu-se, também, que as ações continuam visando principalmente às mães, e raramente os pais, visto que as empresas não têm trabalhado planos específicos para eles, o que foi explanado na última fala da empresa $\mathrm{D}$, onde os entrevistados pontuaram que culturalmente os pais aparentam estar menos envolvidos nas atividades parentais que as mães. Isso aumenta ainda mais a visão de que a incumbência de cuidar dos filhos se resume a mãe, majorando ainda mais a barreira intangível entre os dois sexos dentro da empresa.

De toda forma, observa-se com otimismo a formalização dos planos de benefício bem como as poucas políticas já escritas, ainda que elas divirjam do esperado. Ao se condensar os tipos de benefícios em documentos formais, que devem ser seguidos por gestores tanto dos níveis estratégicos como operacionais, indica que mais adiante possa ocorrer o afunilamento em uma política global, ampla, democrática e duradoura, onde os esforços da maternidade sejam assumidos pelas empresas, o que permitirá reter as colaboradoras em condições favoráveis. Tomando por base as constatações acima, surgem diversas sugestões para trabalhos futuros relacionados a este tema.

De antemão, a temática de como as empresas encaram a maternidade deve ser talvez a mais urgente. Isso se dá pela carência de estudos que versam sobre a compreensão holística do processo parental, o que permitiria compreender se para as empresas a maternidade só é significativa nos primeiros anos, ou um processo que se prolonga da iniciação da gravidez até a entrada na fase adulta. Outro tema que pode ser investigado mais a fundo diz respeito a conciliação dos pais com o trabalho, uma vez que, é muito ressaltado ultimamente a importância da presença paterna junto aos recém-nascidos como forma de estreitar os laços afetivos.

Mais, enxerga-se a oportunidade de pesquisas mais abrangentes com as próprias funcionárias, de como elas percebem os esforços traçados pelas companhias para as acolher enquanto mães. Fora isso, reparou-se que há espaço para pesquisar de maneira mais técnica os resultados alcançados pelas empresas que têm absorvido políticas para a maternidade, ou seja, buscando dados mais quantitativos que possam estimular outras companhias a se aperfeiçoarem nesta direção.

\section{Referências}

Andrade, T. (2016). Mulheres no mercado de trabalho: onde nasce a desigualdade? Estudo Técnico Câmara dos Deputados, Consultoria Legislativa. Recuperado de: https://bityli.com/pbhdH.

Ansiliero, G. \& Rodrigues, E. B. O. (2007). Histórico e Evolução Recente da Concessão de Salários-Maternidade no Brasil. Informe de Previdência Social. 19(02).

Basilio, A. (2014). Mulheres melhoram o desempenho no trabalho após ser mãe. Revista Crescer. https://bityli.com/5z84X.

Baylão, A. L. S. \& Schettino, E. M. O. (2014). A inserção da mulher no mercado de trabalho brasileiro. XI Simpósio de Excelência em Gestão e Tecnologia. $3(02)$.

Botello, H. A., \& Alba, A. L. (2014). O efeito da maternidade sobre os salários femininos na américa latina. Semestre Económico, 17(36), 13-38.

Brasil, A. (2017, março 10). Maternidade e carreira profissional: as boas práticas empresariais sustentáveis e produtivas. https://bityli.com/Jtevs.

Brasil. (2018). Senado Federal. Projeto de Lei do Senado, n. 72, de 2017. https://www25.senado.leg.br/web/atividade/materias/-/materia/128502.

Carmo, J. (2019). Mesmo com maior grau de escolaridade, mulheres ganham menos que homens. https://bityli.com/Ag2fQ.

Carvalho Neto, A. M. de, Tanure, B., \& Andrade, J. (2010). Executivas: carreira, maternidade, amores e preconceitos. RAE eléctron., 9(1).

Dalpino, C. (2018). As dificuldades da volta ao trabalho depois da licença-maternidade. https://bityli.com/3IpJn.

Fernandes, V. M. B., et. al. (2018). Condutas de gestores relacionadas ao apoio ao aleitamento materno nos locais de trabalho. Texto \& Contexto Enfermagem, 27(3).

Fiorin, P. C., Oliveira, C. T., \& Dias A. C. G. (2014). Percepções de mulheres sobre a relação entre trabalho e maternidade. Revista Brasileira de Orientação Profissional, 15(1), 25-35. 
Fonseca, A. L. B. (2011). Gravidez, maternidade e análise comportamental da cultura: crenças e atitudes de agentes comunitárias de saúde e adolescentes grávidas do sertão do brasil. (Tese de doutorado). Universidade Federal do Espírito Santo, Vitória, ES, Brasil. Recuperado de: https://bityli.com/kfcnv.

Grant, W. H. A. (2001). Maternidade, o Trabalho e a Mulher. LEPSI IP/FE. Universidade de São Paulo. São Paulo, SP, Brasil.

Guimarães, R. P.F., \& Martinez, L. (2017). Desafios da Reforma Trabalhista. Revista dos Tribunais.

IBGE. (2012). Instituto Brasileiro de Geografia e Estatística. Mulher no mercado de trabalho: perguntas e respostas. Pesquisa mensal de emprego - pme. https://bityli.com/bnz2c.

IBGE. (2017). Instituto Brasileiro de Geografia e Estatística. Síntese de indicadores sociais: uma análise das condições de vida da população brasileira: 2017. http://renastonline.ensp.fiocruz.br/sites/default/files/arquivos/recursos/liv101459.pdf.

Lauschner, M. C. X. G. da S., Cavalcante, M. S., \& Torres, I. C. (2012). Mulher e mercado de trabalho: conquistas, drama e sofrimento. IV Seminário de Trabalho e Gênero - protagonismo, ativismo, questões de gênero revisitadas.

Lessa, D. (2007). Especial Licença-Maternidade 2 - Evolução das leis e costumes sobre licença-maternidade no Brasil. Câmara dos Deputados. Reportagem especial. https://bityli.com/2Ulne.

Maes, J. (2017). Essas empresas souberam acolher suas profissionais mães. E todo mundo saiu ganhando. Recuperado de: https://bityli.com/bOnXD.

Mamona, K. S. (2013). Maioria das brasileiras não volta ao trabalho após a licença-maternidade. Recuperado de: https://bityli.com/AGQX2.

Moraes, R., \& Galiazzi, M. do C. (2006). Análise textual discursiva: processo reconstrutivo de múltiplas faces. Ciência. \& educação, 12(1), 117-128.

Olivieri, M. (2019). Como as empresas podem reter mais mães no mercado de trabalho? https://bityli.com/yarJu.

Pasinato, L., \& Mosmann, C. P. (2016). Transição para a parentalidade e a coparentalidade: casais que os filhos ingressaram na escola ao término da licençamaternidade. Avances en Psicología Latinoamericana, 34(1), 129-142.

Pinheiro, J. L., \& Gois, J. B. H. (2013). Amplitude da gestão da(s) diversidade(s) - implicações organizacionais e sociais. ReCaPe Revista de Carreiras e Pessoas, 3(2).

Saraiva, L. A.S., \& Irigaray, H.A.R. (2009). Políticas de diversidade nas organizações: uma questão de discurso? Revista Administração Empresarial, 49(3), 337-348.

Spricigo, C. (2017). Gestão empresarial e ascensão feminina: estudo de caso numa empresa da região sul do Brasil. II Seminário Nacional de Serviço Social, Trabalho e Politicas Sociais Universidade Federal de Santa Catarina Florianópolis.

Trevisan, R. (2015). Como não sofrer na volta ao trabalho depois da licença maternidade. Revista cláudia. https://bityli.com/mrbbi.

Trevizan, K. (2019). Pesquisa mostra que 30\% das mulheres deixam trabalho por causa dos filhos, homens são 7\%. https://bityli.com/7d7ak.

Uchôa, M. R. (2016). Mulher e mercado de trabalho no brasil: um estudo sobre igualdade efetiva: baseado no modelo normativo espanhol. ltr.

Umeda, G. \& Trindade, C. (2004). Possíveis Definições Para As Políticas Empresariais: Um Estudo Bibliográfico. Política dos negócios e economia de empresas.

Vasconcelos, I. S. (2013). Mulher e Mercado de Trabalho no Brasil: Notas de uma História Em Andamento. Revista Examãpaku. 3(2).

Vergara, S. C. (2009). Projetos e Relatórios de Pesquisa em Administração (11a ed.). Atlas.

Yin, R. K. (1984). Case study research: design and methods. Sage.

Yin, R. K. (2001). Estudo de caso: Planejamento e Métodos (2a ed.). Bookman. 